\title{
The Impact Of Communication On The Accounting Firm/Client Relationship
}

Timothy R. Koski, (E-mail: tkoski@mtsu.edu), Middle Tennessee State University

Craig R. Ehlen, (E-mail: CEhlen@usi.edu), University of Southern Indiana

Carl L. Saxby, (E-mail: CSaxby@usi.edu), University of Southern Indiana

\begin{abstract}
This paper presents the results of a study designed to gather information on communication between an accounting firm and its clients. We first provide descriptive information on clients' perceptions regarding the frequency, method, and importance of communication with their accounting firm. We then provide evidence on the relationship between effective communication and both client satisfaction and accounting firm/client conflict. We find that that the use of effective communication techniques by an accounting firm is positively related to client satisfaction and negatively related to firm/client conflict. The overall results of this study suggest that accounting firms can effectively use collaborative communication, which focuses on using communication to build better relationships between firms, to manage client relations.
\end{abstract}

\section{Introduction}

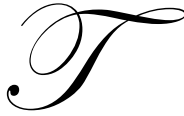

he importance of communication in business relationships is well established. In fact, communication has been described as the most important element to the successful interchange between firms (Bleeke and Ernst, 1993, p. xvi). Marketing researchers have made significant strides in understanding how communication between firms can be effectively managed (see e.g., Mohr, Fisher and Nevin, 1996; 1999).

One method used by firms to manage relationships with customers is collaborative communication, which focuses on using communication to build better relationships between firms. Collaborative communication involves four components: (1) frequency of communication, (2) direction of communication (emphasizing two-way communication), (3) formality of communication (having set communication policies and procedures in place), and (4) the use of influence tactics to emphasize common goals between the firms (Mohr, Fisher and Nevin, 1996; 1999). Collaborative communication has been found to be effective in increasing client satisfaction with and commitment to a firm (Anderson and Weitz, 1992; Mohr, Fisher and Nevin, 1999; Morgan and Hunt, 1994; Keith, Jackson, and Crosby, 1990; Cannon 1999).

Although a significant amount of research has been conducted on using communication to manage client relationships in various settings, we are unaware of any dealing specifically with accounting firms. While there is considerable evidence that effective communication skills are positively related to success in accounting (see e.g., Stowers and White, 1999; Gingras, 1987; Henry and Razzouk, 1988), such research has only examined communication at the individual level. Research on communication at the accounting firm level is lacking. This study extends research on firm-to-firm communication to the accounting firm setting by examining the relationship between effective communication and two important attributes of the accounting firm/client relationship: client satisfaction and firm/client conflict. Extending this research to the accounting firm setting will fill a significant gap in the accounting literature.

This paper reports the results of a study focusing on methods of communication between an accounting firm and its clients, and the relationship between effective communication and both client satisfaction and firm/client conflict. We first provide descriptive information on clients' perceptions regarding the frequency, 
method, and importance of communication with their accounting firm. Information comparing the firm's communication methods to how clients prefer to be communicated with can assist accounting firms in establishing more effective communication policies and in managing client relationships better. We then provide evidence that effective communication is positively related to client satisfaction and negatively related to firm/client conflict.

\section{Hypothesis Development}

Firms can and do use different elements of collaborative communication to effectively communicate with their clients. Previous studies have found that collaborative communication is positively related to client satisfaction (Anderson and Weitz, 1992; Mohr, Fisher and Nevin, 1999; Morgan and Hunt, 1994; Keith, Jackson, and Crosby, 1990; Cannon 1999). None of these studies, however, involved the accounting firm/client relationship.

Mohr, Fisher \& Nevin (1999) examined the effect of collaborative communication on different channel outcomes, including channel member satisfaction. Using a sample of computer manufacturers, they found that collaborative communication was positively related to satisfaction with the manufacturer. In addition, the positive effect of collaborative communication on satisfaction was stronger when channel members were independent from the manufacturer. In particular, collaborative communication was more positively related to satisfaction when ownership and franchising were not used, and when the manufacturer lacked power over the dealer.

Mohr, Fisher and Nevin's (1999) finding that collaborative communication was more positively related to satisfaction when the manufacturer lacked power over the dealer provides useful information when applied to the accounting firm setting. Accounting firms have less control over their clients than the manufacturing companies examined in previous collaborative communication research. Because of the lack of control characteristic of the accounting firm/client relationship, accounting firms should be able to effectively increase client satisfaction by using collaborative communication.

We measured three elements of communication: frequency of communication, methods of communication, and the importance of issues discussed. Conceptually, effective communication arises when communication is frequent, bi-directional, and when more important issues are discussed. As noted above, this ideal mix of communication techniques should lead to increased client satisfaction. As stated in the null form:

H1: Deviation from the ideal mix of collaborative communication techniques will result in lower client satisfaction.

We also examined whether effective communication is related to accounting firm/ client conflict. Conflict in a channel relationship has been defined in various ways. Bowersox, Cooper, Lambert and Taylor (1980) define conflict as "a situation in which one member of the channel perceives another member as engaging in behavior designed to injure, thwart, or gain resources at its expense." Excessive conflict is detrimental to channel relationships.

Communication breakdown is one potential cause of channel conflict (Stern and Heskett, 1969). We hypothesize that accounting firms can use effective communication techniques to minimize communication breakdown and therefore reduce channel conflict. The use of an ideal mix of communication techniques should lead to a decrease in firm/client conflict. As stated in the null form:

H2: Deviation from the ideal mix of collaborative communication techniques will result in higher accounting firm/client conflict.

\section{Methodology}

This research was conducted by mail survey. The survey instrument was developed by the researchers and designed to gather information on communication between an accounting firm and its clients. The survey instrument collected information on (1) frequency of communication, (2) the method of communication actually 
used by the accounting firm, (3) the method of communication preferred by clients, and (4) the importance of the issues discussed. Demographic data on the clients also was collected.

We also collected information on client satisfaction and conflict. Client satisfaction was measured on a five-point Likert-type scale: The following five questions were designed to provide multiple measures of client satisfaction: (1) "In general, I am pretty satisfied with my CPA firm," (2) "Overall, my CPA firm is a good company to do business with," (3) "I want to retain my CPA firm," (4) "Overall, my CPA firm's policies and programs benefit my company," and (5) "Overall, my CPA firm is very fair." Respondents also were asked whether they felt (1) anger, (2) frustration, (3) resentment, or (4) hostility as they reflected on their relationship with their CPA firm. Respondents' answers to these four questions, as measured on a five-point Likert-type scale, were designed to provide multiple measures of firm/client conflict.

The survey was mailed to all 292 sole proprietorship, partnership, and corporate clients of a large regional accounting firm. (Clients that were either estates or trusts and clients for whom preparing personal federal or state income tax returns was the only professional service rendered were not included in the sample.) The survey was addressed to the primary client contact person for coordinating professional services with the accounting firm. A second request was sent to non-respondents one month after the original survey was mailed. Usable responses were received from 154 clients, a response rate of $53 \%$.

\section{Sample Characteristics}

The 154 clients included in data analysis are a representative sample of the accounting firm's clients. As shown in Tables 1 and 2, the sample contained a wide range of industries and client sizes.

Table 1

Industry of Participating Clients

$\underline{\text { Industry }}$
Manufacturing
Construction
Wholesale/Retail
Not-for-profit
Health care
Other
Missing data

Total

\begin{tabular}{c} 
Number \\
\hline 17 \\
20 \\
46 \\
18 \\
9 \\
42 \\
2 \\
\hline
\end{tabular}

$\underline{\underline{154}}$

Table 2

Size of Participating Clients

Annual Revenue
Less than $\$ 500,000$
$\$ 500,001-\$ 2,000,000$
$\$ 2,000,001-\$ 10,000,000$
$\$ 10,000,001-\$ 20,000,000$
Greater than $\$ 20,000,000$
Missing data

Total

\begin{tabular}{c} 
Number \\
\hline 26 \\
43 \\
55 \\
14 \\
11 \\
5 \\
\hline
\end{tabular}

$\underline{\underline{154}}$

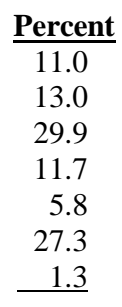

$\underline{100.0}$ 
Respondents were asked what percent of contact with their accounting firm was related to auditing, consulting, tax services, and financial statement preparation, respectively. As reported in Table 3, respondents used their accounting firm for a wide variety of services.

Table 3

Type of Contact with Participating Clients

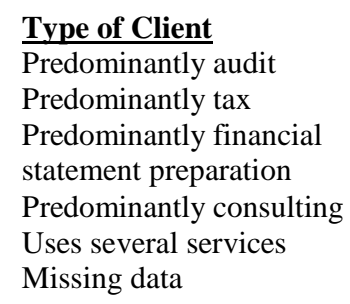

\begin{tabular}{rr} 
Number & Percent \\
\hline 28 & 18.2 \\
57 & 37.0 \\
& \\
21 & 13.6 \\
6 & 3.9 \\
38 & 24.7 \\
4 & 2.6 \\
\hline
\end{tabular}

$\underline{\underline{154}} \underline{\underline{100.0}}$

Tables 4 through 8 summarize the position, experience, gender, age, and education level of the person within each client firm who answered the survey. Individual respondents held a variety of positions in their firms and had diverse experience and educational backgrounds. In general, however, the individual respondents were experienced professionals who held positions of authority in their company. The wide range of client firms and individual respondents included in the data analysis improves the generalizability of our results.

Table 4

Position of Individual Respondent

\author{
$\underline{\text { Position }}$ \\ Owner/General Manger \\ President/CEO \\ Vice-President/CFO \\ Controller \\ Accounting Manager \\ Other \\ Missing data
}

Total

\begin{tabular}{cc} 
Number & Percent \\
46 & 29.9 \\
52 & 33.8 \\
15 & 9.7 \\
19 & 12.3 \\
11 & 7.1 \\
8 & 5.2 \\
3 & 2.0 \\
\hline
\end{tabular}

$\underline{\underline{154}} \underline{\underline{100.0}}$
Table 5

Experience of Individual Respondent

(Years in Industry)

\begin{tabular}{l} 
Years of Experience \\
\hline Less than 6 \\
$6-9$ \\
$10-15$ \\
$16-20$ \\
$21-30$ \\
More than 30 \\
Missing data
\end{tabular}

Total

\begin{tabular}{c} 
Number \\
\hline 15 \\
11 \\
30 \\
25 \\
46 \\
21 \\
6 \\
\hline
\end{tabular}

$\underline{\underline{154}}$

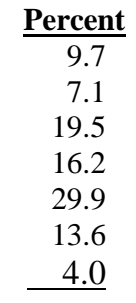

$\underline{\underline{100.0}}$ 
Table 6

Gender of Individual Respondent

Gender
Female
Male
Missing data

Total

$\begin{array}{r}\text { Number } \\ \hline 52 \\ 101 \\ 1 \\ \hline\end{array}$

$\underline{\underline{154}}$

Table 7

Age of Individual Respondent

\author{
Age \\ Less than 40 \\ $40-49$ \\ $50-59$ \\ 60 or more \\ Missing data
}

Total

\begin{tabular}{c} 
Number \\
\hline 25 \\
61 \\
40 \\
21 \\
7 \\
\hline
\end{tabular}

$\underline{\underline{154}}$
Percent

33.8

65.6

0.6

$\underline{\underline{100.0}}$

Table 8

Education Level of Individual Respondent

\begin{tabular}{lcr} 
Education Level & Number & Percent \\
\cline { 2 - 3 } High school graduate & 12 & 7.8 \\
Some college & 43 & 27.9 \\
College graduate & 55 & 35.7 \\
Some postgraduate study & 18 & 11.7 \\
Masters degree or more & 24 & 15.6 \\
Missing data & 2 & $\underline{1.3}$ \\
Total & $\underline{154}$ & $\underline{100.0}$
\end{tabular}

\section{Analysis Of Results}

\section{Frequency, Methods, Importance and Preferred Mode of Communication}

Respondents were asked whether they were satisfied with the frequency of communication with their accounting firm. The results are reported in Table 9. The large majority of clients $(79.2 \%)$ felt that their accounting firm communicated with them as often as expected. $11.7 \%$ felt that frequency of communication was not enough. Only $7.8 \%$ of clients surveyed thought communication exceeded expectations.

Table 9

Frequency of Communication with Accounting Firm

(Client's Perception)

Frequency of Communication
Not often enough (1)
As often as expected (2)
Exceeds expectations (3)
Missing data
Total

Frequency of Communication

Missing data

Total

\section{Percent \\ 16.2 \\ 39.6 \\ 26.0 \\ 4.6}

$\underline{\underline{100.0}}$ 
Tables 10 reports the methods of communication used by the accounting firm. The accounting firm communicated with their clients primarily by telephone (76.7\%), and regular mail (14.9\%).

Table 10

Usual Method of Communication

(How the Client is Contacted)

\begin{tabular}{lcr} 
Method of Communication & Frequency & Percent \\
\cline { 2 - 3 } Personal visit (3) & 8 & 5.2 \\
Telephone (2) & 118 & 76.6 \\
Fax (1) & 1 & .6 \\
Mail (1) & 23 & 14.9 \\
E-mail (1) & 2 & 1.3 \\
Other (1) & 1 & .7 \\
Missing data & $\underline{1}$ & .7 \\
Total & $\underline{\underline{154}}$ & $\underline{\underline{100.0}}$
\end{tabular}

Table 11 reports the clients' perception of the importance of issues discussed during communication with their accounting firm. As can be seen, over $97 \%$ of respondents felt that the issues discussed were either very important $(74.0 \%)$ or somewhat important $(23.4 \%)$. Clients do not appear to be bothered by communication regarding issues they consider unimportant.

Table 11

Importance of Issues Discussed

(Client's Perception)

Importance of Issues
Frequently unimportant (3)
Somewhat important (2)
Very important (1)
Missing data
Total

\begin{tabular}{rr} 
Number & Percent \\
\hline 3 & 1.9 \\
36 & 23.4 \\
114 & 74.0 \\
$\frac{1}{\underline{154}}$ & $\underline{.7}$ \\
\hline$\underline{100.0}$
\end{tabular}

We also measured the client's preferred mode of communication with their accounting firm. As can be seen in Table 12, personal contact is important to accounting firm clients. Almost $80 \%$ of clients preferred either a personal visit $(11.0 \%)$ or a telephone call $(67.5 \%)$.

Table 12

Preferred Mode of Communication (How the Client Wants to be Contacted)

\begin{tabular}{lrr} 
Mode of Communication & Frequency & Percent \\
\cline { 2 - 3 } Personal visit & 17 & 11.0 \\
Telephone & 104 & 67.5 \\
Fax & 2 & 1.4 \\
Mail & 15 & 9.7 \\
E-mail & 10 & 6.5 \\
Other & 1 & .7 \\
Missing data & $\underline{5}$ & $\underline{3.2}$ \\
Total & $\underline{\underline{154}}$ & $\underline{100.0}$
\end{tabular}




\section{Cumulative Communication Index}

Conceptually, effective communication arises when the communication is frequent, personal (bidirectional), and when important issues are discussed. We measured these three variables of effective communication to determine their relationship to client satisfaction and firm/client conflict. Participant responses were ranked 1,2, or 3 on the three variables of effective communication measured. These index scores are reported in Tables 9, 10, and 11. In Table 9, for example, communication frequency that exceeds expectations is assigned a score of 3, communication frequency as often as expected is assigned a score of 2, and communication frequency not often enough is assigned a score of 1 . The usual method of communication used and importance of issues discussed were similarly ranked. These communication rankings were then multiplied to produce an interactive index of effective communication. The higher the index score, the more effective the communication. The lowest possible score (an index of 1) would require infrequent communication via impersonal modes about unimportant topics. The highest possible score (an index of 27) would require communication frequency that exceeds expectations via personal visits and would concern very important topics. Table 13 reports the cumulative communication index scores.

Table 13

Cumulative Communication Index Scores

\begin{tabular}{|c|c|c|c|c|}
\hline $\begin{array}{c}\text { Index Scores } \\
\text { (frequency X method X importance) }\end{array}$ & Frequency & Percent & Valid \% & Cum. \% \\
\hline 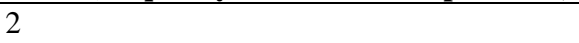 & 2 & 1.3 & 1.3 & 1.3 \\
\hline 3 & 4 & 2.6 & 2.6 & 3.9 \\
\hline 4 & 13 & 8.4 & 8.6 & 12.5 \\
\hline 6 & 21 & 13.6 & 13.8 & 26.3 \\
\hline 8 & 20 & 13.0 & 13.2 & 39.5 \\
\hline 9 & 4 & 2.6 & 2.6 & 42.1 \\
\hline 12 & 74 & 48.1 & 48.7 & 90.8 \\
\hline 18 & 12 & 7.8 & 7.9 & 98.7 \\
\hline 27 & 2 & 1.3 & 1.3 & \\
\hline Missing Data & $\underline{2}$ & $\underline{1.3}$ & & \\
\hline Total & $\underline{154}$ & $\underline{\underline{100.0}}$ & $\underline{\underline{100.0}}$ & $\underline{\underline{100.0}}$ \\
\hline
\end{tabular}

\subsection{Relationship of Communication to Client Satisfaction}

A profile deviation methodology was used to assess the relationship between effective communication and client satisfaction. This analysis uses deviations in the pattern of a given organizational unit from its ideal type or pattern to test at the aggregate level (Conrad, Brown and Harmon, 1997). Initially, an ideal profile is theoretically or empirically derived. Following the procedure used by Conrad, Brown, and Harmon (1997), our ideal profile was empirically derived by using a calibration sample consisting of the top $10 \%$ of the cumulative communication index scores. The highest scores in this index exhibit the most effective communication - the ideal profile. We divided the sample into the top $10 \%$ of firms (the ideal profile) and the lower $90 \%$ of firms. We then tested whether the top $10 \%$ (those 14 firms with an index score $=>18$ ) differed from the lower $90 \%$ (those 138 firms with an index score $<18$ ) in terms of client satisfaction. Table 14 reports the results of this test.

The five scores on the individual satisfaction variables were combined into an overall satisfaction score. As measured by the overall satisfaction score, the relationship between effective communication and client satisfaction is statistically significant and in the hypothesized direction. This supports Hypothesis One. Overall, clients who perceived their accounting firm as using frequent, personal communication about important issues were more satisfied then those who did not. 
Table 14

Relationship Between Effective Communication and Client Satisfaction

\begin{tabular}{|c|c|c|c|c|c|c|c|}
\hline Indicator & Group & $\mathbf{N}$ & Mean & Std. Dev. & t-test & Df & Sig. \\
\hline Generally pretty satisfied & $\begin{array}{c}>=18 \\
<18\end{array}$ & $\begin{array}{c}14 \\
138\end{array}$ & $\begin{array}{l}4.5714 \\
4.3116\end{array}$ & $\begin{array}{l}.6462 \\
.7528\end{array}$ & 1.245 & 150 & .215 \\
\hline CPA is a good company & $\begin{array}{c}>=18 \\
<18\end{array}$ & $\begin{array}{c}14 \\
138 \\
\end{array}$ & $\begin{array}{l}4.7143 \\
4.3841 \\
\end{array}$ & $\begin{array}{l}.6112 \\
.6762 \\
\end{array}$ & 1.755 & 150 & .081 \\
\hline Want to retain CPA firm & $\begin{array}{c}>=18 \\
<18\end{array}$ & $\begin{array}{c}14 \\
138 \\
\end{array}$ & $\begin{array}{l}4.8571 * \\
4.2681 *\end{array}$ & $\begin{array}{l}.3631 \\
.8154 \\
\end{array}$ & 2.670 & 150 & .008 \\
\hline Policy and programs benefit my company & $\begin{array}{c}>=18 \\
<18\end{array}$ & $\begin{array}{c}14 \\
137\end{array}$ & $\begin{array}{l}4.5000 \\
4.0876\end{array}$ & $\begin{array}{l}.6504 \\
.8356\end{array}$ & 1.790 & 149 & .075 \\
\hline CPA firm is very fair & $\begin{array}{c}>=18 \\
<18\end{array}$ & $\begin{array}{c}14 \\
137\end{array}$ & $\begin{array}{l}4.6429 * \\
4.0803 *\end{array}$ & $\begin{array}{l}.6333 \\
.8140\end{array}$ & 2.507 & 149 & .013 \\
\hline Summed Satisfaction Score & $\begin{array}{c}>=18 \\
<18\end{array}$ & $\begin{array}{c}14 \\
138\end{array}$ & $\begin{array}{l}23.2857^{*} \\
21.0725^{*}\end{array}$ & $\begin{array}{l}2.7012 \\
3.4969\end{array}$ & 2.297 & 150 & .023 \\
\hline
\end{tabular}

* Statistically significant at the .05 level.

Although the overall satisfaction score was significant at the .05 level, not all of the individual measures of client satisfaction were. They were, however, all in the predicted direction. Two items ("I want to retain my CPA firm" and "My CPA firm is very fair") were significant at the .05 level. Two other items ("My CPA firm is a good company to do business with" and "My CPA firm's policies and programs benefit my company") were significant at the .10 level.

\section{Relationship Between Effective Communication and Firm/Client Conflict}

We also used a profile deviation methodology to assess the relationship between effective communication and firm/client conflict (Conrad, Brown and Harmon, 1997). As with client satisfaction, we divided the sample into the top $10 \%$ of firms (the ideal profile) and the lower $90 \%$ of firms. We then tested whether the top $10 \%$ (those firms with an index score =>18) differed from the lower $90 \%$ (those firms with an index score <18) in terms of client conflict. Table 15 reports the results of this test.

Table 15

Relationship Between Effective Communication and Firm/Client Conflict

\begin{tabular}{|l|c|c|c|c|c|c|c|}
\hline \multicolumn{1}{|c|}{ Indicator } & Group & $\mathbf{N}$ & Mean & Std. Dev. & t-test & Df & Sig. \\
\hline Anger & $>=18$ & 14 & $1.0000^{*}$ & .0000 & -2.080 & 145 & .039 \\
& $<18$ & 133 & $1.4361^{*}$ & .7819 & & & \\
\hline Frustration & $>=18$ & 14 & 1.2143 & .8018 & -1.820 & 148 & .071 \\
& $<18$ & 136 & 1.7941 & 1.1618 & & & \\
\hline Resentment & $>=18$ & 14 & $1.0000^{*}$ & .0000 & -1.988 & 145 & .049 \\
& $<18$ & 133 & $1.4211^{*}$ & .7902 & & & \\
\hline Hostility & $>=18$ & 14 & 1.0000 & .0000 & -1.972 & 145 & .051 \\
& $<18$ & 133 & 1.3835 & .7253 & & & \\
\hline Summed Conflict Score & $>=18$ & 14 & $4.2143^{*}$ & .8016 & 1.975 & 149 & .050 \\
& $<18$ & 137 & $5.8978^{*}$ & 3.1699 & & & \\
\hline
\end{tabular}

The four scores on the individual conflict variables were combined into an overall conflict score. As measured by the overall conflict score, the relationship between effective communication and firm/client conflict is statistically significant at the .05 level and in the hypothesized direction. This supports Hypothesis Two. Overall, firm/client conflict was less where clients perceived their accounting firm as using frequent, personal communication about important issues. 
Although the overall firm/client conflict score was significant at the .05 level, not all of the individual measures of conflict were. They were, however, all in the predicted direction. Anger and resentment were significant at the .05 level. Frustration and hostility were significant at the .10 level.

\section{Discussion}

This study provides evidence that accounting firms can increase client satisfaction and decrease firm/client conflict by using effective communication techniques. Both the demographic data and the evidence supporting Hypotheses One and Two demonstrate the importance of frequent, personal communication with clients. Accounting firms should make a concerted effort to stay in touch with their clients. As the old saying goes, they should "let their fingers do the walking." Accounting firms can increase client satisfaction and decrease client conflict by simply picking up the phone and staying in touch with clients.

Personal communication involves two-way communication - an important element in collaborative communication. Although further research is needed, our finding of a strong client preference for personal communication suggests that collaborative communication may be an effective way to manage an accounting firm/client relationship.

The results of this study reveal other strategies that accounting firms should consider. E-mail communication was preferred by $6.5 \%$ of clients, but used by accounting firms only $1.3 \%$ of the time. Regular mail service, on the other hand, was preferred by only $9.7 \%$ of clients, but used by accounting firms $14.9 \%$ of the time. E-mail is an easy and relatively inexpensive form of communication. Accounting firms may be able to improve client relations by increasing e-mail communication. Given the ease of pressing a button and responding to e-mail, communication via e-mail is an easier and more timely form of two-way communication than regular mail. The use of two-way communication is an important component of collaborative communication that can easily and inexpensively be increased by the use of e-mail.

We preformed several ANOVAs to determine if the preferred method of communication varied by type of respondent. None of the ANOVAs was significant. The preferred method of communication did not vary as a function of industry type or size of the client, either. It also did not vary as a function of the personal characteristics (position in the firm, years of experience, gender, age, or education level) of the individual respondents. Finally, we found no significant difference in the method of communication preferred based on the type of services (e.g., audit, tax, financial statement preparation, bookkeeping) the communication regarded.

These findings suggest that accounting firms can effectively manage client relationships by establishing set communication policies - an important component of managing client relationships by collaborative communication. Accounting firms should establish consistent communication policies that call for frequent personal contact (mainly telephone calls and personal visits) for clients of all sizes, in all types of industries, and in all areas of practice.

In conclusion, this study extends communications research into the accounting firm setting and demonstrates that accounting firms can effectively use collaborative communication techniques to manage client relationships. Effective communication is positively related to client satisfaction and negatively related to firm/client conflict. Further research examining the use of collaborative communication by accounting firms is warranted.

\section{References}

1. Anderson, J.C., and B. Weitz. 1992. "The use of pledges to build and sustain commitment in distribution channels". Journal of Marketing Research, 29(1): 18-34.

2. Bleeke, J., and D. Ernst. 1993. Collaborating to Compete. New York: John Wiley \& Sons.

3. Bowersox, D.J., B.B. Cooper, D.M. Lambert, and D.A. Taylor. 1980. Management in Marketing Channels. New York: McGraw-Hill Company. 
4. Cannon, J.T. 1999. "Buyer-seller relationships in business markets". Journal of Marketing Research, 36(4): 439-461.

5. Conrad, C.A., G. Brown, and H.A. Harmon. 1997. "Customer satisfaction and corporate culture: A profile deviation analysis of a relationship marketing outcome". Psychology and Marketing, 14(7): 663674.

6. Gingras, R.T. 1987. "Writing and the certified public accountant". Journal of Accounting Education, 5: 127-137.

7. Henry, L.G., and N.Y. Razzouk. 1988. "The CPA's perception of accounting education: Implications for curriculum development". The Accounting Educator's Journal, 1(1): 105-117.

8. Keith, J., D. Jackson, and L. Crosby. 1990. "Effects of alternative types of influence strategies under different channel dependence structures". Journal of Marketing, 54(3): 30-41.

9. Mohr, J., R.J. Fischer, and J.R. Nevin. 1996. "Collaborative communication in interfirm relationships: Moderating effects of integration and control". Journal of Marketing, 60(3) 103-126.

10. Mohr, J., R.J. Fisher, and J.R. Nevin. 1999. “Communicating for better channel relationships". Marketing Management, 8(2): 38-45.

11. Morgan, R., and S. Hunt. 1994. "The commitment-trust theory of relationship marketing”. Journal of Marketing, 58: 20-38.

12. Stern, L.W., and J.L. Heskett. 1969. "Conflict management in interorganizational relations: A conceptual framework," in Behavioral Dimensions, L.W. Stern, ed. (Boston: Houghton Mifflin Company) pp. 285297.

13. Stowers, R.H., and G.T. White. 1999. "Connecting accounting and communication: A survey of public accounting firms". Business Communication Quarterly. 62(2): 23-40. 